\title{
Association of human leukocyte antigen-DRB1 alleles with chronic hepatitis $B$ virus infection in the Han Chinese of Northeast China
}

\author{
YU HAN $^{1 *}$, ZHEN-YU JIANG $^{2 *}$, LI-XIN JIAO ${ }^{1}$, CHENG YAO $^{2}$, QIAN-FEI LIN ${ }^{1}$, NING MA ${ }^{2}$, \\ RUI-QING JU ${ }^{1}$, FAN YANG ${ }^{1}$, JIANG-HONG YU ${ }^{1}$ and LIN CHEN $^{1}$ \\ ${ }^{1}$ Jilin Blood Center, Changchun, Jilin 130033; ${ }^{2}$ First Hospital of Jilin University, Changchun, Jilin 130021, P.R. China
}

Received November 12, 2011; Accepted February 13, 2012

DOI: $10.3892 / \mathrm{mmr} .2012 .800$

\begin{abstract}
Human leukocyte antigen (HLA) class II molecule is an integral component of the immune response on which the majority of host genetic studies have concentrated. Many different HLA-II alleles have been demonstrated to play roles in HBV infection. PCR-SSOP methods were applied to determine the HLA-DRB1 genotypes of 769 unrelated healthy individuals from Han Chinese of Northeast China. The frequencies of HLA-DRB1*09 in hepatitis B virus (HBV)-infected subjects were higher compared to those in the control group. Frequencies of HLA-DRB1*04 and ${ }^{*} 13$ in the HBV-infected group were significantly lower compared to those in the healthy control group. Frequencies of HLA-DRB1*12 in the cirrhosis and liver cancer groups were significantly higher than those in the chronic hepatitis $\mathrm{B}(\mathrm{CHB})$ patients. The frequency of LA-DRB1 ${ }^{0} 03$ in the CHB patient group was significantly higher compared to that in the asymptomatic hepatitis B carrier patients. The above results suggest that the host HLA-II gene is an important factor in the determination of the outcome of HBV infection.
\end{abstract}

\section{Introduction}

Hepatitis B virus (HBV) infection is a serious issue. Approximately two billion people worldwide are infected with HBV (1). Individuals infected with HBV may be asymptomatic hepatitis B carriers (ASC), but many of these individuals may progressively develop chronic hepatitis $\mathrm{B}(\mathrm{CHB})$, liver cirrhosis (LC) and hepatocellular carcinoma (HCC). Susceptibility to

Correspondence to: Mrs. Lin Chen, Institute of Blood Transfusion, Jilin Blood Center, 5916 Ziyou Avenue, Changchun, Jilin 130033, P.R. China

E-mail: ccxzsys@yahoo.com.cn

*Contributed equally

Key words: chronic hepatitis B, hepatitis B virus, human leukocyte antigen, Northeast Han Chinese, PCR-SSOP
HBV infection and the outcome of post-infection vary among individuals; however, the underlying mechanisms are poorly understood (2-4). HBV replication in hepatocytes per se does not directly damage the liver, while HBV-induced immune responses may attack HBV-infected hepatocytes, mediating liver damage. Apparently, the status of immunity of an individual is a pivotal determinant for the susceptibility of HBV infection and disease course $(3,4)$.

Human leukocyte antigen (HLA) plays an important role in the human immune response by presenting antigens to T cells, regulating $\mathrm{T}$ cell immunity. The polymorphism of HLA genes is one of the most important genetic factors in determining the host immune response and is related to the susceptibility of individuals to HBV infection $(5,6)$. Previous research has shown that the HLA-I genes are in linkage disequilibrium with CHB and the polymorphisms of HLA-II alleles are associated with susceptibility to $\mathrm{CHB}$ (7). However, the association is racially and geographically dependent $(6,8-10)$.

The prevalence of HBV infection is extremely high in China and many people with $\mathrm{HBV}$ infections develop $\mathrm{CHB}$ and some progress to the onset of cirrhosis (11). A follow-up study (1-18.4 years) revealed that 23 and $4.4 \%$ of $\mathrm{CHB}$ patients with hepatitis $\mathrm{B}$ early antigen ( $\mathrm{HBeAg}$ )-negative serological status progress to the development of cirrhosis and $\mathrm{HCC}$, respectively $(12,13)$. However, there is no information concerning whether the association of HLA with the susceptibility and development of chronic HBV exists in the Han Chinese of Northeast China.

In the present study, we characterized the phenotypes of HLA-DRB1 in subjects with HBV infection and healthy controls, and evaluated the potential association of the HLA-DRB1 polymorphism with HBV susceptibility, ASC, HBV-related CHB, LC and HCC in the Han Chinese of Northeast China.

\section{Materials and methods}

Subjects. A total of 396 patients (241 male and 155 female, with mean age of $49 \pm 18$ years) with chronic HBV infection (positive hepatitis B surface antigen ( $\mathrm{HBsAg}$ ), normal or abnormal liver enzymes, including 87 ASC, 120 CHB patients, 103 cases with HBV-related LC and 86 cases of HCC) were selected as 
Table I. Demographic and clinical characteristics of the different patient groups.

\begin{tabular}{|c|c|c|c|c|}
\hline & \multicolumn{4}{|c|}{ Patient groups } \\
\hline & ASC & CHB & $\mathrm{LC}$ & $\mathrm{HCC}$ \\
\hline No. of cases & 87 & 120 & 103 & 86 \\
\hline Gender (male/female) & $49 / 38$ & $73 / 47$ & $61 / 42$ & $52 / 34$ \\
\hline Age (year) & $29 \pm 6$ & $31 \pm 6$ & $46 \pm 7$ & $52 \pm 8$ \\
\hline $\operatorname{ALT}(\mathrm{IU} / \mathrm{l})$ & $40 \pm 10$ & $185 \pm 120$ & $177 \pm 55$ & $79 \pm 12$ \\
\hline $\mathrm{HBeAg}^{+}(\%)$ & $6 / 87(7.3)$ & $101 / 120(84.8)$ & 43/103 (41.7) & $7 / 86(8.6)$ \\
\hline Anti-HBeAb (\%) & $78 / 87(90.3)$ & $90 / 120(29.7)$ & $27 / 103(45.0)$ & $8 / 86(32.0)$ \\
\hline HBV-DNA & $\leq 10^{5}$ & $>10^{5}$ & $>10^{5}$ & $>10^{5}$ \\
\hline
\end{tabular}

ASC, asymptomatic hepatitis B carriers; CHB, chronic hepatitis B; LC, liver cirrhosis; HCC, hepatocellular carcinoma; HBeAg, hepatitis B early antigen; HBV-DNA, hepatitis B virus-DNA.

the HBV-infected patient group. All of the patients as well as 400 healthy subjects were recruited at the outpatient and inpatient services of the Department of Infectious Diseases at the First Affiliated Hospital, Jilin University from April 2007 to December 2008. The healthy subjects were blood donors and all subjects were unrelated Han Chinese of Jilin Province, China. Individual patients were diagnosed according to the criteria set forth in the Guidelines of Hepatitis B Prevention and Treatment by the Chinese Society of Hepatology (14), and the diagnoses of the patients with HCC were confirmed by pathological examination. Individuals with a history of familial inherited diseases, immune deficiency, other chronic diseases, such as diabetes, hypertension, multiple sclerosis, rheumatoid arthritis, cardiovascular diseases or with HCV or HDV infection were excluded. The demographic and clinical characteristics of the study subjects are presented in Table I.

Written informed consent was obtained from all individuals and the experimental protocol was approved by the Ethics Committee of the First Hospital of Jilin University.

DNA extraction and HLA-DRB1 $1^{*}$ genotyping. Blood samples (approximately $2 \mathrm{ml}$ ) were collected from individual participants and genomic DNA was extracted using the DNA extraction kit, according to the manufacturer's instructions (Invitrogen). After qualification and quantification of the isolated DNA with ratios of $\mathrm{A} 230 / 280$ at 1.65-1.90, the DNA samples were adjusted to $\geq 50 \mathrm{ng} / \mu \mathrm{l}$. The genotypes of individual DNA samples were characterized by the PCR-SSOP typing analysis using the HLA-DRB1 genotyping kit, according to the manufacturer's instructions (DYNAL). Briefly, the second exon of the HLA-DRB1 gene was amplified by PCR using previously reported primers (15). The PCR reactions in duplicate were performed at $95^{\circ} \mathrm{C}$ for 5 min and subjected to 34 cycles of $95^{\circ} \mathrm{C}$ for $20 \mathrm{sec}, 64^{\circ} \mathrm{C}$ for $20 \mathrm{sec}$ and $72^{\circ} \mathrm{C}$ for $45 \mathrm{sec}$, followed by extension at $72^{\circ} \mathrm{C}$ for $5 \mathrm{~min}$. The biotinylated PCR products were subsequently characterized by $2 \%$ agarose gel electrophoresis and visualized under UV exposure. The expected size of the product was approximately $270 \mathrm{bp}$.

Subsequently, the amplified DNA was denatured and hybridized with complementary DNA probes coupled to microbeads. After washing, the microbeads were probed with phycoerythrin (PE)-conjugated streptavidin at room temperature for $1 \mathrm{~h}$. The fluorescent intensity of the biotinylated PCR product on each coded oligobead was measured using a Luminex-200 apparatus. The HLA-DRB1*genotype of individual samples was determined using the Genosearch Typing software-Luminex 100 IS (version 2.3), and the HLA typing of individuals was analyzed using the Dynal AccuPlex software.

Serological tests. Serological analyses of HBV, HCV and HDV infection and the concentrations of serum HBV DNA were analyzed using enzyme-linked immunosorbent assay (ELISA) and fluorescence quantitative PCR, respectively, by the Testing Center of the First Affiliated Hospital, Jilin University. A cut-off value of $\leq 10^{5}$ copies $/ \mathrm{ml}$ was regarded as negative. Liver function tests were analyzed using a Beckman Coulter LX20 analyzer by the Testing Center of the First Affiliated Hospital, Jilin University.

Statistical assay. Allele frequencies were calculated using the direct counting method. The differences in allele frequencies among groups were analyzed using the $\chi^{2}$ test and Fisher's exact test, and the association of allele genotypes with the disease was estimated by the odds risk (OR) and 95\% confidence interval (CI) using statistical software SPSS 17.0. $\mathrm{P}<0.05$ was considered to indicate a statistically significant difference and was further corrected by the Bonferroni correction (Pc).

\section{Results}

Frequencies of the HLA-DRB1 alleles. The frequencies of HLA-DRB1 alleles between the $396 \mathrm{HBV}$-infected patients and 400 control subjects were compared (Table II). The frequency of HLA-DRB1*09 $(22.79 \%, 147$ cases $)$ in the patients was significantly higher than *09 (12.83\%, 91 cases) in the controls $(\mathrm{P}<0.05)$. In contrast, the frequencies of HLA-DRB1*04 (8.64\%, 63 cases) and *13 (3.80\%, 29 cases) in the patients were significantly lower than HLA-DRB1*04 $(12.52 \%, 89$ cases $)$ and *13 (6.52\%, 49 cases) in the controls, respectively $(\mathrm{P}<0.05)$. There was no significant difference in the distribution of other HLA-DRB1 alleles between the patients and controls in this population. 
Table II. Distribution of the HLA-DRB1 alleles in the study participants.

\begin{tabular}{|c|c|c|c|c|c|c|c|c|}
\hline \multirow[t]{2}{*}{$\begin{array}{l}\text { Allele } \\
\text { DRB1* }\end{array}$} & \multicolumn{2}{|c|}{$\begin{array}{c}\text { HBV-infected } \\
\text { patients }(n=396)\end{array}$} & \multicolumn{2}{|c|}{$\begin{array}{l}\text { Control } \\
(n=400)\end{array}$} & \multirow[t]{2}{*}{$\chi^{2}$} & \multirow[t]{2}{*}{ P-value } & \multirow[t]{2}{*}{ OR } & \multirow[t]{2}{*}{$95 \%$ CI } \\
\hline & $\mathrm{PN}$ & $\mathrm{AF}(\%)$ & PN & $\mathrm{AF}(\%)$ & & & & \\
\hline 01 & 12 & 1.54 & 18 & 2.30 & 1.162 & 0.867 & 0.668 & $0.320-1.397$ \\
\hline 03 & 46 & 6.17 & 86 & 4.58 & 1.693 & 0.210 & 1.348 & $0.858-2.116$ \\
\hline 04 & 63 & 8.64 & 89 & 12.52 & 4.632 & $0.033^{\mathrm{a}}$ & 0.69 & 0.492-0.969 \\
\hline 07 & 80 & 11.24 & 91 & 12.83 & 0.674 & 0.419 & 0.875 & $0.637-1.203$ \\
\hline 08 & 39 & 5.18 & 43 & 5.68 & 0.166 & 0.734 & 0.912 & $0.584-1.423$ \\
\hline 09 & 147 & 22.79 & 91 & 12.83 & 16.162 & $0.000^{\mathrm{a}}$ & 1.776 & $1.339-2.865$ \\
\hline 10 & 6 & 0.76 & 15 & 1.91 & 3.818 & 0.076 & 0.399 & $0.154-1.086$ \\
\hline 11 & 44 & 5.88 & 56 & 7.53 & 1.411 & 0.286 & 0.782 & $0.520-1.175$ \\
\hline 12 & 95 & 13.63 & 111 & 16.11 & 1.249 & 0.296 & 0.846 & $0.631-1.186$ \\
\hline 13 & 29 & 3.80 & 49 & 6.52 & 5.183 & $0.027^{\mathrm{a}}$ & 0.583 & $0.364-0.932$ \\
\hline 14 & 70 & 9.70 & 56 & 7.53 & 1.846 & 0.194 & 1.288 & $0.893-1.857$ \\
\hline 15 & 143 & 22.03 & 186 & 20.30 & 0.385 & 0.553 & 1.085 & $0.838-1.406$ \\
\hline 16 & 18 & 2.33 & 11 & 1.39 & 1.793 & 0.194 & 1.668 & $0.783-3.555$ \\
\hline
\end{tabular}

HBV, hepatitis B virus; PN, positive number; AF, allele frequency; OR, odds ratio; CI, confidence interval. ${ }^{\text {aP }}<0.05$ vs control.

Table III. Distribution of the HLA-DRB1 alleles in the ASC and CHB groups.

\begin{tabular}{|c|c|c|c|c|c|c|}
\hline \multirow{2}{*}{$\begin{array}{l}\text { Allele } \\
{\text { DRB }{ }^{*}}^{*}\end{array}$} & \multicolumn{2}{|c|}{ ASC (87) } & \multicolumn{2}{|c|}{ CHB (120) } & \multirow[b]{2}{*}{ P-value ${ }^{a}$} & \multirow[b]{2}{*}{ OR } \\
\hline & $\mathrm{PN}$ & $\mathrm{AF}(\%)$ & $\mathrm{PN}$ & $\mathrm{AF}(\%)$ & & \\
\hline 01 & 2 & 1.15 & 4 & 1.67 & & \\
\hline 03 & 6 & 3.45 & 21 & 8.75 & 0.042 & 0.372 \\
\hline 04 & 12 & 6.90 & 21 & 8.75 & & \\
\hline 07 & 15 & 8.62 & 25 & 10.42 & & \\
\hline 08 & 7 & 4.02 & 16 & 6.67 & & \\
\hline 09 & 32 & 18.39 & 44 & 18.33 & & \\
\hline 10 & 1 & 0.57 & 3 & 1.25 & & \\
\hline 11 & 8 & 4.60 & 17 & 7.08 & & \\
\hline 12 & 13 & 7.47 & 20 & 8.33 & & \\
\hline 13 & 5 & 2.87 & 6 & 2.50 & & \\
\hline 14 & 14 & 8.05 & 26 & 10.83 & & \\
\hline 15 & 32 & 18.39 & 40 & 16.67 & & \\
\hline 16 & 3 & 1.72 & 8 & 3.33 & & \\
\hline
\end{tabular}

ASC, asymptomatic hepatitis B carriers; $\mathrm{CHB}$, chronic hepatitis B. $\mathrm{PN}$, positive number; AF, allele frequency; OR, odds ratio. ${ }^{\text {a Signifi- }}$ cant P-values are shown only; CHB vs. ASC.

Association of HLA-DRB1 alleles with CHB and ASC. The frequencies of HLA-DRB1 alleles and their relative risk for ASC and CHB were further analyzed (Table III). The frequency of HLA-DRB1*03 (8.75\%) in the CHB patients was significantly higher than the frequency $(3.45 \%)$ in the ASC group $(\mathrm{P}<0.05, \mathrm{OR}=0.372)$. However, there was no significant difference in the distribution of other HLA-DRB1 alleles between patients and controls in this population.
Association of HLA-DRBI alleles with CHB, LC and HCC. The frequencies of the HLA-DRB1 alleles and their relative risk for $\mathrm{CHB}, \mathrm{HBV}$-related liver cirrhosis and $\mathrm{HCC}$ were analyzed (Table IV). The frequencies of HLA-DRB1*12 in the patients with HBV-related liver cirrhosis (15.05\%) and HCC $(18.02 \%)$ were significantly higher than the frequency $(8.33 \%)$ in the CHB patients $(\mathrm{P}<0.05, \mathrm{OR}=1.949$ and $\mathrm{P}<0.05, \mathrm{OR}=2.418$, respectively). However, there was no significant difference in the frequencies of HLA-DRB1 alleles between the patients with $\mathrm{HBV}$-related liver cirrhosis and the patients with $\mathrm{HCC}(\mathrm{P}>0.05)$.

\section{Discussion}

The HLA genotype has been thought to be a genetic factor for the prediction of the susceptibility of individuals to HBV infection and prognosis of the disease in certain populations $(3,4)$. The association of HLA alleles with the susceptibility of individuals to HBV infection and disease progression varies since multiple factors, such as geography and ethnicity, affect this association (6,8-10). To investigate the association of the frequency of HLA-DRB1 alleles with the susceptibility of individuals to HBV infection in the Han Chinese of Northeast China, we characterized the genotypes of 396 patients with ASC, CHB, HBV-related liver cirrhosis or $\mathrm{HCC}$ and 400 healthy subjects. We found that the frequency of HLA-DRB1*09 in the HBV-infected patients was significantly higher than that in the healthy controls, suggesting that the HLA-DRB1*09 alleles are associated with increased risk for the infection and progression of $\mathrm{HBV}$ and $\mathrm{CHB}$ in the Han Chinese of Northeast China. The results are consistent with a previous report (16), which showed a significantly higher frequency of HLA-DRB1*09 in CHB patients.

To investigate the potential association of HLA-DRB1 genotypes and persistent infection of HBV in this population, we compared the frequencies of HLA-DRB1 alleles between 
Table IV. Distribution of HLA-DRB1 alleles in the CHB, LC and HCC groups.

\begin{tabular}{|c|c|c|c|c|c|c|c|c|c|c|}
\hline \multirow{2}{*}{$\begin{array}{l}\text { Allele } \\
\text { DRB1* }^{*}\end{array}$} & \multicolumn{2}{|c|}{$\mathrm{CHB}(\mathrm{n}=120)$} & \multicolumn{2}{|c|}{$\mathrm{LC}(\mathrm{n}=103)$} & \multirow[b]{2}{*}{ Pc-value ${ }^{a}$} & \multirow[b]{2}{*}{ OR } & \multicolumn{2}{|c|}{$\mathrm{HCC}(\mathrm{n}=86)$} & \multirow[b]{2}{*}{ Pc-value ${ }^{b}$} & \multirow[b]{2}{*}{ OR } \\
\hline & $\mathrm{PN}$ & $\mathrm{AF}(\%)$ & PN & $\operatorname{AF}(\%)$ & & & PN & $\operatorname{AF}(\%)$ & & \\
\hline 01 & 4 & 1.67 & 4 & 1.94 & & & 2 & 1.16 & & \\
\hline 03 & 21 & 8.75 & 11 & 5.34 & & & 8 & 4.65 & & \\
\hline 04 & 21 & 8.75 & 19 & 9.22 & & & 11 & 6.40 & & \\
\hline 07 & 25 & 10.42 & 25 & 12.14 & & & 15 & 8.72 & & \\
\hline 08 & 16 & 6.67 & 10 & 4.85 & & & 6 & 3.49 & & \\
\hline 09 & 44 & 18.33 & 41 & 19.90 & & & 30 & 17.44 & & \\
\hline 10 & 3 & 1.25 & 1 & 0.49 & & & 1 & 0.58 & & \\
\hline 11 & 17 & 7.08 & 11 & 5.34 & & & 8 & 4.65 & & \\
\hline 12 & 20 & 8.33 & 31 & 15.05 & 0.036 & 1.949 & 31 & 18.02 & 0.004 & 2.418 \\
\hline 13 & 6 & 2.50 & 11 & 5.34 & & & 7 & 4.07 & & \\
\hline 14 & 26 & 10.83 & 18 & 8.74 & & & 12 & 6.98 & & \\
\hline 15 & 40 & 16.67 & 38 & 18.45 & & & 33 & 19.19 & & \\
\hline 16 & 8 & 3.33 & 4 & 1.94 & & & 3 & 1.74 & & \\
\hline
\end{tabular}

CHB, chronic hepatitis B; LC, liver cirrhosis; HCC, hepatocellular carcinoma. PN, positive number; AF, allele frequency; OR, odds ratio;

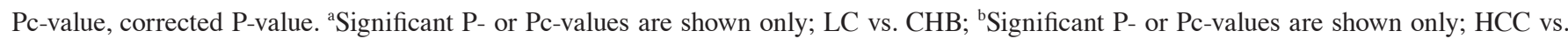
CHB.

the HBV-infected patients and healthy controls. We found that the HLA-DRB1*03 allele was more frequent in the HBV higher load group than in the ASC lower replication group, suggesting that HLA-DRB1*03 may be associated with persistent infection of the hepatitis B virus $(17,18)$. We also found that the frequencies of the HLA-DRB1*04 and *13 alleles in the HBV-infected patients were significantly lower than those in healthy controls, suggesting that these alleles may be associated with a reduced risk for the development of CHB even after infection with HBV. Our results agree with previous findings that the HLA-DRB1*04/*06, HLA-DRB1*11/*12, HLA-DRB1*1101/*1104 are associated with the clearance of HBV (16,19-21). Association of the HLA-DRB1*13 with viral clearance is well established $(22,23)$. Diepolder et al and Karayiannis et al found that individuals carrying HLA-DRB1*13 mounted a strong virus specific $\mathrm{CD}^{+}{ }^{+}$and $\mathrm{CD}^{+} \mathrm{T}$ lymphocyte response to the $\mathrm{HBV}(17,18)$, suggesting a beneficial effect of HLA-DRB1*13 in more proficient antigen presentation. The mechanisms underlying the association of the HLA-DRB1*13 with HBV clearance are largely attributed to the HLA-DRB1*13-mediated anti-HBV immune responses (20). Notably, the frequency of the HLA-DRB1*13 allele in Asians is much lower than that in Caucasians, which may contribute to the high prevalence of HBV infection in Asians. We are interested in further investigating the mechanisms by which the HLA-DRB1*04 and "13 alleles reduce the susceptibility of the Han Chinese to HBV infection.

Analysis of the potential association of HLA-DRB1 alleles with the progression of $\mathrm{CHB}$ revealed that the frequency of the HLA-DRB1*12 allele in HBV-related liver cirrhosis and patients with $\mathrm{HCC}$ was significantly higher than that in $\mathrm{CHB}$ patients, suggesting that the allele could be a candidate genetic factor for the progression of CHB into liver cirrhosis and HCC.
Our results were consistent with a previous report that the HLA-DRBI* $1201 /{ }^{*} 1202$ allele is associated with an increased risk for the development of HBV-related liver cirrhosis, and the HLA-DRBl*04 allele for the development of HCC (24-26). The inconsistent association of HLA-DRBl alleles with the progression of HBV infection in different regions of the Han Chinese may be attributed to varying geographical and environmental factors. We recognized our study in a relatively small population, and many data categories were based on a few cases. Thus, a nationwide collaborative study with a large population is warranted to clarify the association of HLA-DRB1 alleles with the susceptibility of the Han Chinese to HBV infection and the progression of CHB into liver cirrhosis and HCC.

In conclusion, our results show that, HLA-DRB1 typing, to a certain extent, is associated with the persistence of $\mathrm{HBV}$, and the HLA genotype may have an impact on the prognosis of HBV infection. To identify the alleles that specifically affect the susceptibility to chronic HBV infection, further investigation should include a larger sample size, with extended analysis of the low-frequency gene locus in the Chinese population, developing the family pedigree of $\mathrm{CHB}$ and the linkage disequilibrium analysis.

\section{References}

1. Lavanchy D: Hepatitis B virus epidemiology, disease burden, treatment, and current and emerging prevention and control measures. J Viral Hepat 11: 97-107, 2004.

2. Thursz M: Genetic susceptibility in chronic viral hepatitis. Antiviral Res 52: 113-116, 2001.

3. Jung MC and Pape GR: Immunology of hepatitis B infection. Lancet Infect Dis 2: 43-50, 2002.

4. Hohler T, Reuss E, Evers N, et al: Differential genetic determination of immune responsiveness to hepatitis B surface antigen and to hepatitis A virus: a vaccination study in twins. Lancet 360: 991-995, 2002 
5. Kwiatkowski D: Genetic dissection of the molecular pathogenesis of severe infection. Intensive Care Med 26 (Suppl 1): S89-S97, 2000.

6. Han KH, Kim KH and Chang HY: Immunogenetics of hepatitis B virus infection. J Gastroenterol Hepatol 17 (Suppl 3): S329-S332, 2002.

7. Zavaglia C, Bortolon C, Ferrioli G, et al: HLA typing in chronic type B, D and C hepatitis. J Hepatol 24: 658-665, 1996.

8. Knolle PA, Kremp S, Hohler T, Krummenauer F, Schirmacher P and Gerken G: Viral and host factors in the prediction of response to interferon-alpha therapy in chronic hepatitis $\mathrm{C}$ after long-term follow-up. J Viral Hepat 5: 399-406, 1998.

9. Zampino R, Lobello S, Chiaramonte M, Venturi-Pasini C, Dumpis U, Thursz $\mathrm{M}$ and Karayiannis P: Intra-familial transmission of hepatitis B virus in Italy: phylogenetic sequence analysis and amino-acid variation of the core gene. J Hepatol 36: 248-253, 2002

10. Carman WF, Thursz M, Hadziyannis S, McIntyre G, Colman K, Gioustoz A, Fattovich G, Alberti A and Thomas HC: Hepatitis B e antigen negative chronic active hepatitis: hepatitis B virus core mutations occur predominantly in known antigenic determinants. J Viral Hepat 2: 77-84, 1995.

11. Liaw YF, Tai DI, Chu CM and Chen TJ: The development of cirrhosis in patients with chronic type B hepatitis: a prospective study. Hepatology 8: 493-496, 1988

12. Liaw YF, Lin DY, Chen TJ and Chu CM: Natural course after the development of cirrhosis in patients with chronic type B hepatitis: a prospective study. Liver 9: 235-241, 1989.

13. Hsu YS, Chien RN, Yeh CT, Sheen IS, Chiou HY, Chu CM and Liaw YF: Long-term outcome after spontaneous HBeAg seroconversion in patients with chronic hepatitis B. Hepatology 35 : 1522-1527, 2002.

14. Chinese Society of Hepatology and Chinese Society of Infectious Diseases: Guideline for the Prevention and Treatment of Chronic Hepatitis B. Liver 10: 348, 2005 (In Chinese).

15. Itoh Y, Mizuki N, Shimada T, Azuma F, Itakura M, Kashiwase K, Kikkawa E, Kulski JK, Satake M and Inoko H: High-throughput DNA typing of HLA-A, -B, -C, and -DRB1 loci by a PCR-SSOPLuminex method in the Japanese population. Immunogenetics 57 : 717-729, 2005

16. Yang G, Liu J, Han S, Xie H, Du R, Yan Y, Xu D and Fan D Association between hepatitis B virus infection and HLA-DRB1 genotyping in Shaanxi Han patients in Northwestern China. Tissue Antigens 69: 170-175, 2007.
17. Diepolder HM, Jung MC, Keller E, et al: A vigorous virusspecific $\mathrm{CD}^{+} \mathrm{T}$ cell response may contribute to the association of HLA-DR13 with viral clearance in hepatitis B. Clin Exp Immunol 113: 244-251, 1998.

18. Karayiannis P, Alexopoulou A, Hadziyannis S, Thursz M Watts R, Seito S and Thomas HC: Fulminant hepatitis associated with hepatitis B virus e antigen-negative infection: importance of host factors. Hepatology 22: 1628-1634, 1995

19. Jiang YG, Wang YM, Liu TH and Liu J: Association between HLA class II gene and susceptibility or resistance to chronic hepatitis B. World J Gastroenterol 9: 2221-2225, 2003.

20. Wu YF, Wang LY, Lee TD, Lin HH, Hu CT, Cheng ML and Lo SY: HLA phenotypes and outcomes of hepatitis B virus infection in Taiwan. J Med Virol 72: 17-25, 2004

21. Hwang SH, Sohn YH, Oh HB, Hwang CY, Lee SH, Shin ES and Lee KJ: Human leukocyte antigen alleles and haplotypes associated with chronicity of hepatitis B virus infection in Koreans. Arch Pathol Lab Med 131: 117-121, 2007.

22. Cao T, Desombere I, Vanlandschoot P, Sallberg M and Leroux-Roels G: Characterization of HLA DR 13-restricted CD4(+) T cell epitopes of hepatitis B core antigen associated with self-limited, acute hepatitis B. J Gen Virol 83: 3023-3033, 2002.

23. Ahn SH, Han KH, Park JY, Lee CK, Kang SW, Chon CY, Kim YS, Park K, Kim DK and Moon YM: Association between hepatitis $B$ virus infection and HLA-DR type in Korea. Hepatology 31: 1371-1373, 2000.

24. Cheng YQ, Lin JS, Huang LH, Tian DY and Xiong P: The association of HLA-DRB1 allele polymorphism with the genetic susceptibility to liver cirrhosis due to hepatitis B virus. Zhonghua Yi Xue Yi Chuan Xue Za Zhi 203: 247-249, 2003 (In Chinese).

25. El-Chennawi FA, Auf FA, Metwally SS, Mosaad YM, El-Wahab MA and Tawhid ZE: HLA-class II alleles in Egyptian patients with hepatocellular carcinoma. Immunol Invest 37: 661-674, 2008

26. Huang YW, Hu CY, Chen CL, et al: Human leukocyte antigenDRB1*1101 correlates with less severe hepatitis in Taiwanese male carriers of hepatitis B virus. J Med Virol 81: 588-593, 2009. 